\title{
Bone Mineral Density of Adolescent Female Tennis Players and Nontennis Players
}

\author{
Kevser Ermin, Scott Owens, M. Allison Ford, and Martha Bass \\ Bone Density Laboratory, The University of Mississippi, 215 Turner Center, University, Oxford, MS 38677, USA \\ Correspondence should be addressed to M. Allison Ford, ford@olemiss.edu \\ Received 29 February 2012; Revised 2 May 2012; Accepted 9 May 2012 \\ Academic Editor: Jun Iwamoto \\ Copyright () 2012 Kevser Ermin et al. This is an open access article distributed under the Creative Commons Attribution License, \\ which permits unrestricted use, distribution, and reproduction in any medium, provided the original work is properly cited.
}

The purpose of this study was to determine differences in bone mineral density (BMD) among adolescent female tennis players (TPs) and nontennis players (NTPs) and to assess body composition as a predictor variable of BMD. Nineteen female TPs and 19 female NTPs, ages 14 to 18 years, participated in this study. Lumbar spine, total hip, femoral neck, forearms BMD, and body composition were assessed using dual-energy X-ray absorptiometry (DXA). Lumbar spine and total hip BMD measurements for TP were greater than NTP. However, these differences were not statistically significant $(P=0.37$ and 0.12 , resp. $)$. TP had significantly greater femoral neck BMD than NTPs $(P=0.02)$. This difference might play an important role in preventing osteoporosis and decreasing the risk of fractures at the hip later in life.

\section{Introduction}

Osteoporosis is as a skeletal condition characterized by loss of bone mineral density [1]. Approximately 10 million Americans have osteoporosis and $80 \%$ of those are women whereas $20 \%$ are men [2]. Peak bone mass (PBM) is a major determinant of bone mass later in life and is attained during the first two decades of life $[3,4]$. Therefore, maximizing the amount of bone gained during childhood and adolescence is essential in preventing osteoporosis and decreasing the risk of fractures later in life [5-9].

Physical activity is one of the most important factors in increasing PBM and preventing osteoporosis [10]. When examining the effects of physical activity on bone mineral density (BMD), type of exercise is important. Specifically, weight bearing exercise is critical in increasing BMD. Most tennis players have significantly greater bone mass and bone area in their dominant arm compared to their nondominant arm [4, 11-15]. However, most of these earlier studies examined BMD of adult tennis players. The purpose of this study was to determine differences in BMD among adolescent female tennis players (TPs) and nontennis players (NTPs).

\section{Materials and Methods}

2.1. Participants. Nineteen female TPs and 19 NTPs between 14 and 18 years of age participated in this study. Permission to participate was obtained from parents and the adolescents provided assent to participate. This study was performed with the approval of The University of Mississippi's Institutional Review Board. TPs were included in the study if they had been playing tennis for a minimum of two years and were playing at least three hours per week [11]. The control group included female adolescents who did not play tennis; however, they may have been involved in other sports competitively or recreationally. All of the subjects were healthy with no known diseases and were not receiving medications known to effect bone metabolism, such as, corticosteroids.

Body mass index (BMI) plays an important role in BMD $[16,17]$; therefore, BMI of TPs and NTPs was matched. Race is also a factor that may affect BMD [2]. All TPs in this study were Caucasians. Therefore, only Caucasian NTPs were included in the control group.

2.2. Procedures. TPs were recruited from local high school tennis teams and a local tennis academy, while the NTPs 
were recruited from local high schools. A letter was sent home with the potential participant giving information on the methods of the study and that participants would need parent's permission to enroll in the study. Once complete, participants were scheduled to come into the Bone Density Laboratory where weight and height were measured using a standard doctor's scale. Total hip, AP lumbar spine, and both forearms BMD and body composition were assessed using a Hologic Delphi-W (Bedford, MA) DXA machine. The forearm scans included the area of the radius and ulna and wrist bones (carpals). The AP lumbar spine scans included the vertebras L1 through L4. The nondominant hip of participants was scanned. Tanner stages were assessed using a questionnaire [18] that is related to the adolescent's pubertal status. Menstrual status was assessed by asking participants if they had regular menstrual cycles and if they had ever experienced amenorrhea. Participants who indicated that they did not have regular menstrual cycles or experienced amenorrhea were eliminated from the study. Physical activity (PA) was assessed using the 7-day Physical Activity Recall Questionnaire [19]. Participants were asked to recall physical activities they engaged in during the previous seven days as being either light (activities of daily living), moderate (active but nonexhausting), or vigorous (made their heart beat rapidly). They recorded only those activities and durations that fell within the moderate or vigorous categories. A weekly physical activity score was computed for each participant as metabolic hours per week (MET hours/week) calculated by multiplying the MET score for each moderate or vigorous activity by the listed duration for each activity and then summed across all seven days. Moderate activities were assigned a MET value of 4 and vigorous activities a MET value of 7 [20].

2.3. Statistical Analysis. One-way ANOVA was used to assess differences between the groups for all BMD, body composition, and physical activity measurements. Multiple regression analysis was used to determine the best predictor of BMD amongst weight, total body lean mass, and total body fat mass. Both $Z$ scores and BMD raw scores were analyzed to determine differences in spine and hip measurements between the groups whereas only BMD raw scores were used to obtain differences in forearms BMD since the DXA software used for this study did not have the database of $Z$ scores for forearms. Significance level was set at $\alpha=0.05$ and data were analyzed using SPSS version 18.0.

\section{Results and Discussion}

Participant characteristics are reported in Table 1. There were no significant differences between the TP and NTP for height, body mass, age, and Tanner Stages.

Results of BMD measurements for both groups are summarized in Table 2 . TP had significantly greater femoral neck BMD than the NTP $(P=0.02$ for $Z$ scores and $P=0.02$ for raw scores). Although TP had greater BMD for lumbar spine and total hip measurements, these differences were not statistically significant ( $P=0.37$ and 0.12 , resp.). When total
TABle 1: Characteristics of participants.

\begin{tabular}{lcc}
\hline & $\begin{array}{c}\text { Tennis players } \\
(n=19)\end{array}$ & $\begin{array}{c}\text { Nontennis players } \\
(n=19)\end{array}$ \\
\hline Age (years) & $16.2 \pm 1.1$ & $16.3 \pm 1.5$ \\
Height $(\mathrm{cm})$ & $164.6 \pm 6.7$ & $165.0 \pm 6.7$ \\
Weight $(\mathrm{kg})$ & $59.0 \pm 7.3$ & $55.9 \pm 6.5$ \\
BMI $\left(\mathrm{kg} / \mathrm{m}^{2}\right)$ & $21.8 \pm 2.7$ & $20.5 \pm 1.8$ \\
Tanner stages (range) & $4-5$ & $4-5$ \\
Calcium intake & $2.7 \pm 0.9$ & $2.7 \pm 1.5$ \\
(servings/week) & $42 \%$ & $32 \%$ \\
Adequate calcium intake & &
\end{tabular}

All values are means and standard deviations.

forearm BMD of the dominant arm and nondominant arm was compared within each group, only TPs had statistically significant differences indicating that dominant arm BMD of the TPs was significantly greater than non-dominant arm BMD $(P<0.001)$. In addition, a side-to-side comparison between TPs and NTPs was not significant $(F=0.39, P=$ 0.53 ). However, a comparison of mean differences of distal $1 / 3$ radius and ulna was compared between TPs and NTPs, a significant difference was found $(t=2.03, P=0.05)$. We did not find a significant difference between the ULNA distal region $(P=0.97)$.

Table 3 displays the mean results of body composition variables for both groups. There were no significant differences for total body percent fat $(P=0.72)$, total body lean mass $(P=0.07)$, and total body fat mass $(P=0.59)$ between the groups. Regression analysis revealed that the combination of the three independent variables (weight, total fat mass, and total lean mass) significantly predicted BMD at the femoral neck and total hip $\left(P<0.001, R^{2}=0.38\right.$; $P=0.03, R^{2}=0.23$, resp.) with lean mass being the best predictor for both measurements.

Results of PA data and tennis playing history are summarized in Table 4. The difference in physical activity between TP and NTP expressed as MET-hours/week did not reach statistical significance $(P=0.24)$.

\section{Discussion}

This study assessed the differences in BMD between adolescent female TPs and NTPs who may have been involved in sports other than tennis. To the best of our knowledge, this is the first study to assess femoral BMD in adolescent female TPs, which includes a physically active nontennis playing control group. The NTP control groups in previous studies have been sedentary. In the present study, $58 \%$ of the control group participants were involved in other sports competitively. The main finding of this study was that TPs had significantly greater femoral neck BMD than NTPs, even though the NTPs participated in significant amounts of nontennis physical activity. This result supports previous research findings suggesting that tennis players have significantly greater femoral neck BMD than controls $[12,21]$. However, tennis players in the previous research were adult 
TABLE 2: Bone mineral density measurements of adolescent tennis players and nontennis players.

\begin{tabular}{|c|c|c|c|c|c|c|}
\hline \multirow{2}{*}{$\operatorname{BMD}\left(\mathrm{g} / \mathrm{cm}^{2}\right)$} & \multirow{2}{*}{$\begin{array}{l}\text { Tennis players } \\
\quad(n=19)\end{array}$} & \multirow{2}{*}{$\begin{array}{l}\text { Nontennis } \\
\text { Players }(n=19)\end{array}$} & \multirow{2}{*}{ Percent difference ${ }^{\S}$} & \multicolumn{3}{|c|}{$95 \%$ confidence interval of the difference } \\
\hline & & & & $P$ & Lower & Upper \\
\hline Total body & $1.154 \pm 0.07$ & $1.137 \pm 0.09$ & 1.5 & .530 & -0.037 & 0.070 \\
\hline Lumbar spine & $1.011 \pm 0.08$ & $1.418 \pm 1.96$ & 28.7 & .372 & -1.319 & 0.505 \\
\hline Total hip & $1.025 \pm 0.08$ & $0.976 \pm 0.12$ & 4.7 & .140 & -0.017 & 0.116 \\
\hline Femoral neck & $0.900 \pm 0.09^{*}$ & $0.820 \pm 0.12$ & 8.9 & .020 & 0.013 & 0.146 \\
\hline Dominant arm & $0.563 \pm 0.05$ & $0.563 \pm 0.05$ & 0 & .971 & -0.033 & 0.032 \\
\hline Nondominant arm & $0.553 \pm 0.04$ & $0.557 \pm 0.05$ & 0.7 & .481 & -0.034 & 0.025 \\
\hline
\end{tabular}

Values other than percentages are means and standard deviations.

$\S$ Percent difference between tennis and nontennis players.

* Tennis players significantly higher than controls $(\alpha=.05)$.

TABle 3: Body composition measurements of adolescent tennis players and nontennis players.

\begin{tabular}{lcc}
\hline & $\begin{array}{c}\text { Tennis players } \\
(n=19)\end{array}$ & $\begin{array}{c}\text { Nontennis players } \\
(n=19)\end{array}$ \\
\hline Total body \% fat & $26.5 \pm 5$ & $27.1 \pm 4.3$ \\
Total body fat mass $(\mathrm{kg})$ & $15.5 \pm 4.8$ & $14.8 \pm 3.2$ \\
Total body lean mass $(\mathrm{kg})$ & $40.0 \pm 4.4$ & $37.4 \pm 4.3$ \\
\hline
\end{tabular}

All values are means and standard deviations.

There was no significant difference found between TPs and NTPs.

TABle 4: Results of 7-Day Physical Activity (PA) Questionnaire and tennis playing history.

\begin{tabular}{lcc}
\hline & $\begin{array}{c}\text { Tennis players } \\
\left(n=19^{*}\right)\end{array}$ & $\begin{array}{c}\text { Non tennis players } \\
(n=19)\end{array}$ \\
\hline $\begin{array}{l}\text { Physical activity (MET } \\
\text { hours/week) } \\
\text { Starting age for playing }\end{array}$ & $53.3 \pm 44.1$ & $36.6 \pm 40.7$ \\
$\begin{array}{l}\text { tennis (yr) } \\
\begin{array}{l}\text { Frequency of playing tennis } \\
\text { days/wk) }\end{array}\end{array}$ & $4.8 \pm 1.2$ & - \\
$\begin{array}{l}\text { Duration of each tennis } \\
\text { session (min) }\end{array}$ & $83.6 \pm 25.6$ & - \\
\hline
\end{tabular}

All values are means and standard deviations.

${ }^{*} n=18$ for MET hours/week due to one set of extreme scores.

male and female tennis players. Previous data have shown that high-impact exercise, such as jumping, increases BMD in the femoral neck [16]. Tennis requires mostly anaerobic, rapid accelerations, and decelerations with twisting components and can produce ground reaction forces 5 to 10 times a person's body weight [22]. Nordstöm et al. [22] observed that badminton players have significantly greater femoral neck BMD than ice hockey players and controls and stated that this difference might be due to the movements executed in the sport. Badminton players are generally subjected to short high-impact bursts when jumping and high strains in unusual directions; during leg lunges forward and fast direction changes from side to side. Furthermore, the ground reaction forces created by a jump may be absorbed first in the feet and joints of the lower extremities in which the created high strains may be a powerful stimuli to increase $\mathrm{BMD}$. The same statement may be true for tennis players. In fact, Nikander et al. (2005) found that female athletes who were subjected to different loading modalities had stronger femoral neck measurements than those not performing these modalities [23]. Again, in 2010, Nikander found that oddimpact exercises were significantly associated with a $20 \%$ thicker cortex around the femoral neck [24]. Therefore, it can be suggested that the movements of tennis playing that produce great ground reaction forces might increase BMD in the femoral neck. Although these cross-sectional data do not allow us to quantify the minimum amount of physical activity necessary to bring about increases in $\mathrm{BMD}$, it is worth noting that the tennis averaged 4.8 tennis sessions/week and 83.6 minutes/session. Thus, of the 53.3 MET hours per week of physical activity they engaged in, $88 \%$ (46.8 MET hours/week) was accounted for by their tennis playing. Whether lesser amounts of weekly tennis playing cause favorable changes in BMD will need to be examined in prospective investigations.

According to the National Osteoporosis Foundation [2] 297,000 osteoporosis related hip fractures occurred in the United States in 2005. Furthermore, approximately 293,000 Americans aged 45 years and older were admitted to hospitals with a fracture of the femoral neck in 2005. Developing high femoral neck and total hip BMD by playing tennis during teenage years might play an important role in osteoporosis prevention and decreasing the risk of fractures at the hip later in life.

In this study, there was no significant difference in lumbar spine BMD between TPs and NTPs. Juzwiak et al. [13] also observed no significant differences in lumbar spine BMD between adolescent male TPs and controls. However, Haapasalo et al. [3] reported that lumbar spine BMD was significantly greater only in tennis players who were at Tanner stages 4 and 5 compared to control group participants who did not participate in sports. We did not find a significantly greater spine BMD for TPs which may be because participants of the NTP group were not sedentary and were involved in activities that might affect their spine BMD. In the current study, all of the TPs and NTPs were at Tanner stages 4 and 5 . When the mean BMD values for the lumbar spine in both studies are compared, TPs in 
the current study had greater values than the tennis players of Haapasalo et al. [25] $\left(0.980 \mathrm{~g} / \mathrm{cm}^{2}\right.$ versus $0.971 \mathrm{~g} / \mathrm{cm}^{2}$ for Tanner Stage 4 and $1.045 \mathrm{~g} / \mathrm{cm}^{2}$ versus $0.963 \mathrm{~g} / \mathrm{cm}^{2}$ for Tanner Stage 5, resp.). The NTPs in this study were as active as TPs and also had higher mean BMD of the lumbar spine when compared to the tennis players in the research of Haapasalo et al. [3].

In the present study, there were no significant differences between TPs and NTPs in forearms BMD. The difference between the dominant arm BMD and the nondominant arm BMD was significant only in TPs. This result supports previous studies which report that side-to-side differences were significantly greater in tennis players $[3,14,25,26]$.

Juzwiak et al. [13] found that adolescent male tennis players have significantly higher lean body mass content and lower fat mass than controls. In contrast, Calbet et al. [12] observed no significant differences in body mass, total lean body mass, total body fat, and the percentage of body fat between tennis players and sedentary controls. In the present study, there were no significant differences in fat mass and lean body mass variables between the TPs and NTPs. The differences from the previous studies might be explained by gender. Data have shown that lean body mass is greater in boys than girls, whereas fat mass is greater in girls than boys in healthy children and adolescents [27]. Furthermore, in the present study, there were no significant differences between the groups for the total minutes of weekly PA, and NTPs had performed significantly greater amounts of moderate PA than TPs. This may explain why there were not significant differences between the groups in body composition measurements. On the other hand, researchers have suggested that in children, lean mass in relation to body height (lean mass/height) should be assessed since sole usage of age and sex specific charts for BMD limits the clinical interpretation of DXA output, and the relation of lean mass to height provides an understanding of the origin of low BMD/age [17]. When lean mass was calculated related to body height (lean mass/height) for this study, TPs had significantly greater total body lean mass than NTPs $(P=$ $0.02)$.

The results of the regression analysis are in agreement with the results of the previous data. In the present study, all of the independent variables were significant predictors of BMD with lean mass being the best predictor among the three independent variables. Previous studies have also shown that lean mass is a significant predictor of BMD in young females $[16,28-30]$. The significant associations between lean mass and BMD have been shown to be performed during force generation by the muscle mass [13]. On the other hand, Seeman et al. [31] suggested that the significant positive correlations between lean mass and BMD could be explained by genetic determinants rather than nongenetic factors.

It has been noted previously that adult tennis players have greater femoral neck BMD than their inactive peers. Our study extends this premise and shows that adolescent female tennis players also have significantly greater femoral neck hip BMD than adolescent female nontennis players who are as physically active as tennis players. Osteoporosis prevention measures are aimed at women who already show the signs of depleted bone mass $[32,33]$. However, primary prevention during childhood and adolescence is critically important [33].

\section{References}

[1] D. L. Glaser and F. S. Kaplan, "Osteoporosis: definition and clinical presentation," Spine, vol. 22, no. 24, supplement, pp. 12S-16S, 1997.

[2] National Osteoporosis Foundation, "Fast Facts," 2008, http:// www.nof.org/osteoporosis/diseasefacts.htm.

[3] H. Haapasalo, P. Kannus, H. Sievänen et al., "Effect of longterm unilateral activity on bone mineral density of female junior tennis players," Journal of Bone and Mineral Research, vol. 13, no. 2, pp. 310-319, 1998.

[4] P. Kannus, H. Haapasalo, M. Sankelo et al., "Effect of starting age of physical activity on bone mass in the dominant arm of tennis and squash players," Annals of Internal Medicine, vol. 123, no. 1, pp. 27-31, 1995.

[5] D. A. Bailey, H. A. McKay, R. L. Mirwald, P. R. E. Crocker, and R. A. Faulkner, "A six-year longitudinal study of the relationship of physical activity to bone mineral accrual in growing children: the University of Saskatchewan Bone Mineral Accrual Study," Journal of Bone and Mineral Research, vol. 14, no. 10, pp. 1672-1679, 1999.

[6] S. Bass, G. Pearce, M. Bradney et al., "Exercise before puberty may confer residual benefits in bone density in adulthood: studies in active prepubertal and retired female gymnasts," Journal of Bone and Mineral Research, vol. 13, no. 3, pp. 500507, 1998.

[7] J. P. Bonjour, G. Theintz, B. Buchs, D. Slosman, and R. Rizzoli, "Critical years and stages of puberty for spinal and femoral bone mass accumulation during adolescence," Journal of Clinical Endocrinology and Metabolism, vol. 73, no. 3, pp. 555-563, 1991.

[8] M. Bradney, G. Pearce, G. Naughton et al., "Moderate exercise during growth in prepubertal boys: changes in bone mass, size, volumetric density, and bone strength: a controlled prospective study," Journal of Bone and Mineral Research, vol. 13, no. 12, pp. 1814-1821, 1998.

[9] K. J. MacKelvie, H. A. McKay, K. M. Khan, and P. R. E. Crocker, "A school-based exercise intervention augments bone mineral accrual in early pubertal girls," Journal of Pediatrics, vol. 139, no. 4, pp. 501-508, 2001.

[10] K. M. Chan, M. Anderson, and E. M. C. Lau, "Exercise interventions: defusing the world's osteoporosis time bomb," Bulletin of the World Health Organization, vol. 81, no. 11, pp. 827-830, 2003.

[11] S. L. Bass, L. Saxon, R. M. Daly et al., "The effect of mechanical loading on the size and shape of bone in pre-, peri-, and postpubertal girls: a study in tennis players," Journal of Bone and Mineral Research, vol. 17, no. 12, pp. 2274-2280, 2002.

[12] J. A. L. Calbet, J. S. Moysi, C. Dorado, and L. P. Rodriguez, "Bone mineral content and density in professional tennis players," Calcified Tissue International, vol. 62, no. 6, pp. 491496, 1998.

[13] C. R. Juzwiak, O. M. S. Amancio, M. S. S. Vitalle, V. L. Szejnfeld, and M. M. Pinheiro, "Effect of calcium intake,tennis playing, and body composition on bone-mineral density of Brazilian male adolescents," International Journal of Sport Nutrition and Exercise Metabolism, vol. 18, no. 5, pp. 524-538, 2008. 
[14] S. Tsuji, N. Tsunoda, H. Yata, F. Katsukawa, S. Onishi, and H. Yamazaki, "Relation between grip strength and radial bone mineral density in young athletes," Archives of Physical Medicine and Rehabilitation, vol. 76, no. 3, pp. 234-238, 1995.

[15] S. Kontulainen, P. Kannus, H. Haapasalo et al., "Good maintenance of exercise-induced bone gain with decreased training of female tennis and squash players: a prospective 5-year follow-up study of young and old starters and controls," Journal of Bone and Mineral Research, vol. 16, no. 2, pp. 195201, 2001.

[16] G. Bedogni, C. Mussi, M. Malavolti et al., "Relationship between body composition and bone mineral content in young and elderly women," Annals of Human Biology, vol. 29, no. 5, pp. 559-565, 2002.

[17] A. Heinonen, P. Kannus, H. Sievänen et al., "Randomised controlled trial of effect of high-impact exercise on selected risk factors for osteoporotic fractures," The Lancet, vol. 348, no. 9038, pp. 1343-1347, 1996.

[18] N. M. Morris and J. R. Udry, "Validation of a self-administered instrument to assess stage of adolescent development," Journal of Youth and Adolescence, vol. 9, no. 3, pp. 271-280, 1980.

[19] R. K. Dishman and M. Steinhardt, "Reliability and concurrent validity for a 7-d re-call of physical activity in college students," Medicine and Science in Sports and Exercise, vol. 20, no. 1, pp. 14-25, 1988.

[20] V. Bissonauth, B. Shatenstein, E. Fafard et al., "Weight history, smoking, physical activity and breast cancer risk among French-Canadian women non-carriers of more frequent BRCA1/2 mutations," Journal of Cancer Epidemiology, vol. 2009, Article ID 748367, 11 pages, 2009.

[21] D. L. Nichols, C. F. Sanborn, S. L. Bonnick, B. Gench, and N. DiMarco, "Relationship of regional body composition to bone mineral density in college females," Medicine and Science in Sports and Exercise, vol. 27, no. 2, pp. 178-182, 1995.

[22] M. J. Alexander, "Biomechanical aspects of lumbar spine injuries in athletes: a review," Canadian Journal of Applied Sport Sciences, vol. 10, no. 1, pp. 1-20, 1985.

[23] R. Nikander, H. Sievänen, A. Heinonen, and P. Kannus, "Femoral neck structure in adult female athletes subjected to different loading modalities," Journal of Bone and Mineral Research, vol. 20, no. 3, pp. 520-528, 2005.

[24] R. Nikander, H. Sievänen, A. Heinonen, R. M. Daly, K. UusiRasi, and P. Kannus, "Targeted exercise against osteoporosis: a systematic review and meta-analysis for optimising bone strength throughout life," BMC Medicine, vol. 8, article 47, 2010.

[25] G. Ducher, D. Courteix, S. Même, C. Magni, J. F. Viala, and C. L. Benhamou, "Bone geometry in response to longterm tennis playing and its relationship with muscle volume: a quantitative magnetic resonance imaging study in tennis players," Bone, vol. 37, no. 4, pp. 457-466, 2005.

[26] P. Kannus, H. Haapasalo, H. Sievänen, P. Oja, and I. Vuori, "The site-specific effects of long-term unilateral activity on bone mineral density and content," Bone, vol. 15, no. 3, pp. 279-284, 1994.

[27] A. Arabi, H. Tamim, M. Nabulsi et al., "Sex differences in the effect of body-composition variables on bone mass in healthy children and adolescents," The American Journal of Clinical Nutrition, vol. 80, no. 5, pp. 1428-1435, 2004.

[28] W. Högler, J. Briody, H. J. Woodhead, A. Chan, and C. T. Cowell, "Importance of lean mass in the interpretation of total body densitometry in children and adolescents," Journal of Pediatrics, vol. 143, no. 1, pp. 81-88, 2003.
[29] S. M. Ott, "Bone density in adolescents," The New England Journal of Medicine, vol. 325, no. 23, pp. 1646-1647, 1991.

[30] M. C. Wang, L. K. Bachrach, M. Van Loan, M. Hudes, K. M. Flegal, and P. B. Crawford, "The relative contributions of lean tissue mass and fat mass to bone density in young women," Bone, vol. 37, no. 4, pp. 474-481, 2005.

[31] E. Seeman, J. L. Hopper, N. R. Young, C. Formica, P. Goss, and C. Tsalamandris, "Do genetic factors explain associations between muscle strength, lean mass, and bone density? A twin study," American Journal of Physiology, vol. 270, no. 2, pp. E320-E327, 1996.

[32] K. Gunter, A. D. G. Baxter-Jones, R. L. Mirwald et al., "Impact exercise increases BMC during growth: an 8-year longitudinal study," Journal of Bone and Mineral Research, vol. 23, no. 7, pp. 986-993, 2008.

[33] K. Poslušná, H. Matějova, and V. Březková, "Risk factors of osteoporosis knowledge and practices among adolescent females," Tech. Rep., School and Health Conference, Brno, Czech Republic, 2008. 


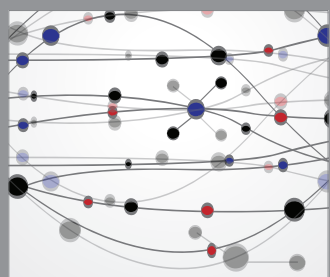

The Scientific World Journal
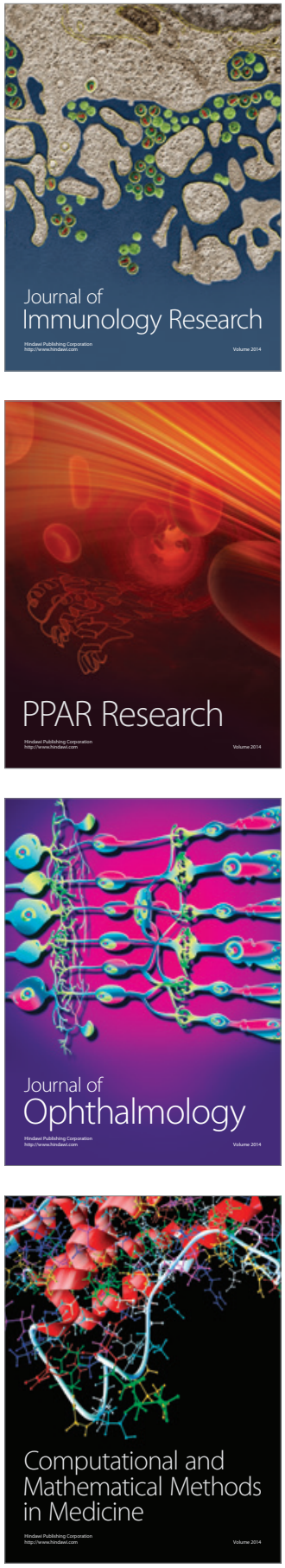

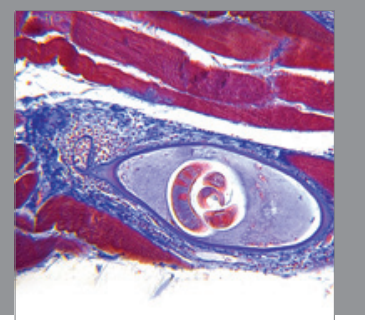

Gastroenterology

Research and Practice
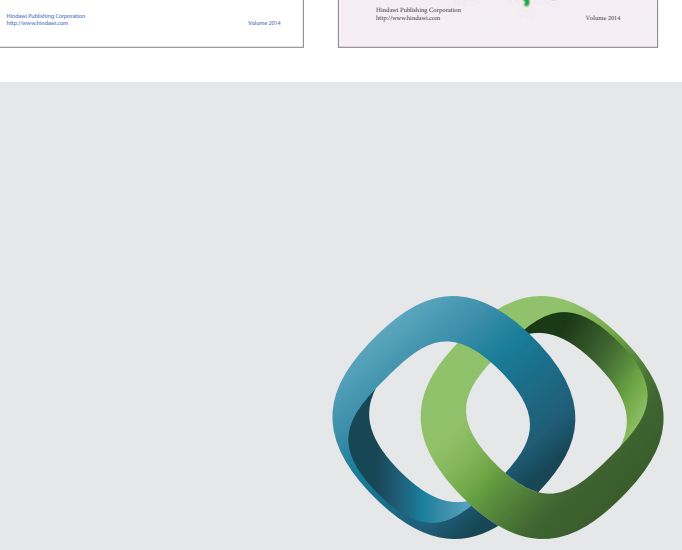

\section{Hindawi}

Submit your manuscripts at

http://www.hindawi.com
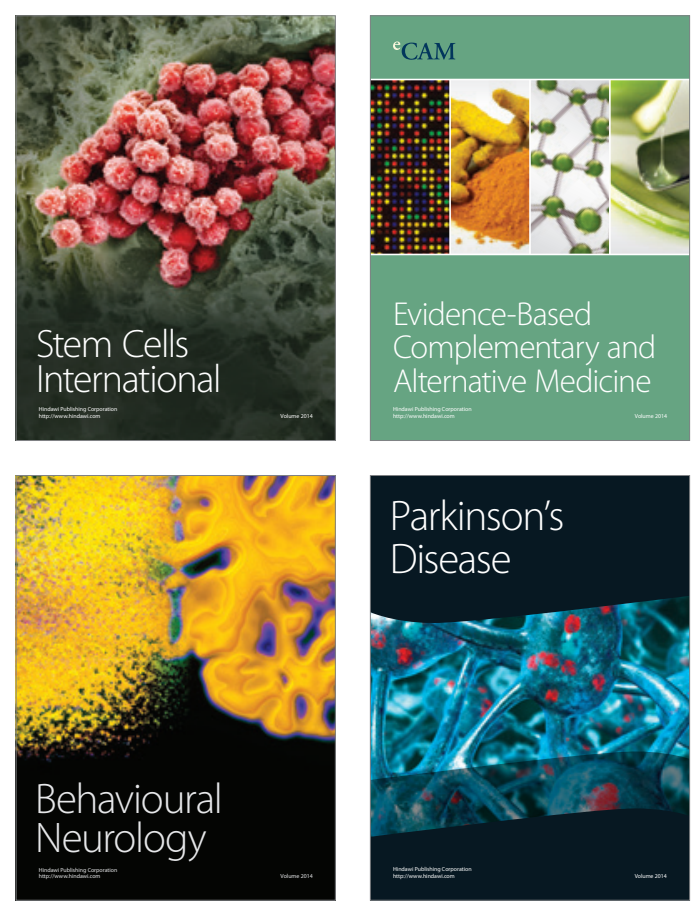

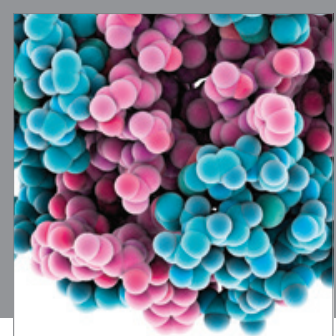

Journal of
Diabetes Research

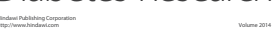

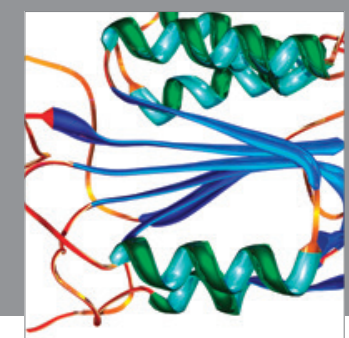

Disease Markers
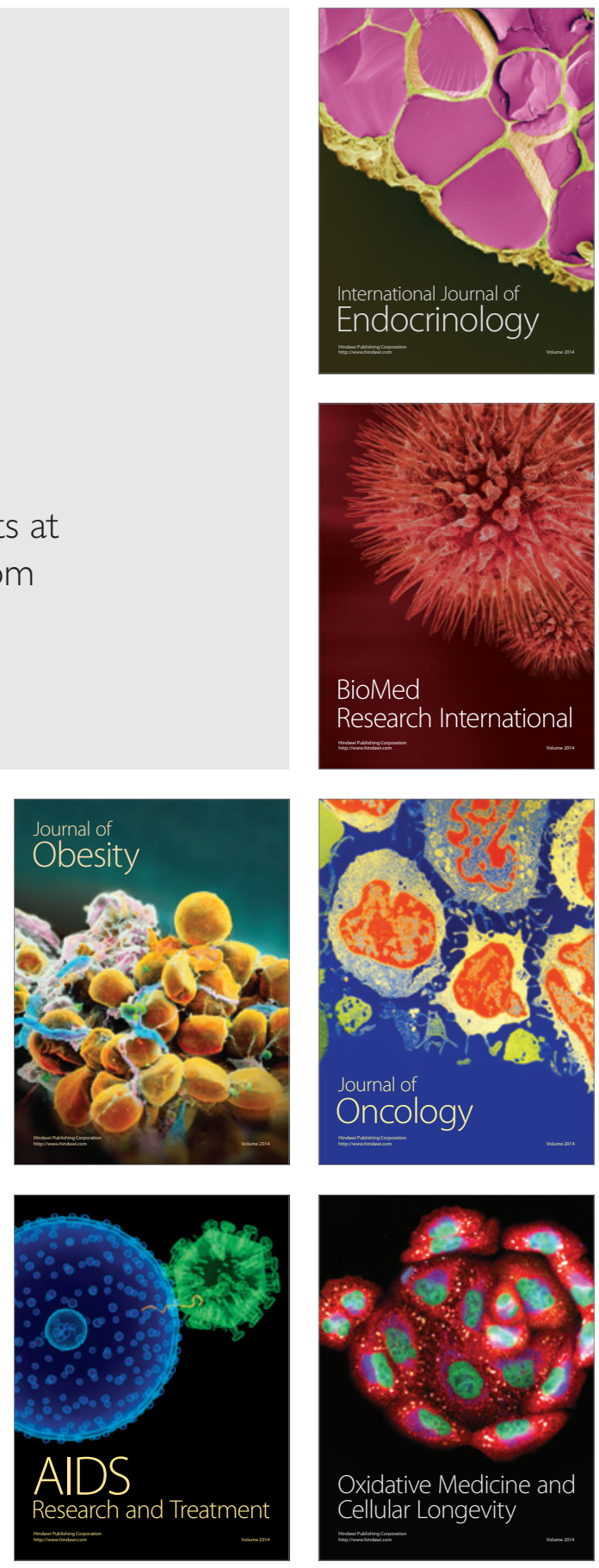